\title{
Technology Diffusion on the International Trade Network ${ }^{*}$
}

\author{
Gary D. Ferrier ${ }^{\S}$ \\ University of Arkansas
}

\author{
Javier Reyes ${ }^{\dagger}$ \\ University of Arkansas
}

Zhen Zhu ${ }^{\ddagger}$
IMT Lucca

August 2015

\begin{abstract}
Technological innovations generate knowledge spillovers-non-innovators benefit through the adoption, imitation, and extension of new technologies. International trade facilitates technology diffusion by providing importing countries access to technical knowledge that they can potentially internalize. Previous studies of the effect of trade on technology diffusion typically only consider the impact of direct (bilateral) trade on indirect measures of technology (e.g., TFP). We contend that the analysis of trade's impact on technology diffusion would be more accurately assessed by using direct measures of specific technologies (e.g., intensity levels) and by allowing for the influence of both the direct and indirect effects of trade in the analysis. The latter is accomplished by modeling the international trade system as a weighted network, which quantifies both direct and indirect trade linkages. Combining trade data with data on the adoption of various technologies, we find that the network effects of trade play a significant role in technology diffusion. In most cases, countries that are better-connected on the trade network have higher technology intensities. Further support for the importance of trade is provided by the finding that for "outdated" technologies, better-connected countries have lower technology intensities due to their adoption of newer, substitute technologies.
\end{abstract}

JEL codes: F10, O33

Keywords: Technology Diffusion, Trade Network, Average Geodesic Distance

\footnotetext{
${ }^{*}$ The authors would like to thank Gisela Rua of the Federal Reserve Board, two anonymous referees, and the participants of the 2013 International Workshop on "Networks and Trade" at KU Leuven, the 2011 Southern Economic Association Conference, and the economics seminars at the University of Arkansas and IMT Lucca for their insightful comments. Any remaining errors are the responsibility of the authors.

$\S$ Gary D. Ferrier, University of Arkansas, Department of Economics, Sam M. Walton College of Business, 1 University of Arkansas, Fayetteville, AR 72701, Tel: (479) 575-6223, gferrier@walton.uark.edu.

† Javier Reyes, University of Arkansas, Department of Economics, Sam M. Walton College of Business, 1 University of Arkansas, Fayetteville, AR 72701, Tel: (479) 575-6079, reyes@uark.edu.

‡ Zhen Zhu, LIME lab, IMT Institute for Advanced Studies, Piazza S. Ponziano, 6, 55100, Lucca, Italy, Tel: +39 05834326611, zhen.zhu@imtlucca.it.
} 


\section{Introduction}

Technological progress has long been viewed as a critical engine for sustainable economic growth and poverty reduction. However, since technological innovation occurs almost exclusively in a few high-income countries (Keller, 2004, 2010), the technological progress at a global level largely depends on knowledge "spillovers” through technology diffusion. ${ }^{1}$ In principle there exist several possible economic channels that facilitate the diffusion of new technologies across countries, the most frequently studied are international trade and foreign direct investment (FDI). ${ }^{2}$ The international flow of goods and services through trade and FDI provide first-hand knowledge about the existence, uses, and benefits of new technologies. ${ }^{3}$ This paper adds to the literature on the effects of trade on the diffusion of technologies across countries by modeling trade as a network of both direct and indirect relationships as well as by examining trade's effect on the diffusion of specific technologies rather than on an aggregate proxy for technology such as total factor productivity (TFP).

When empirically testing the effects of trade on technology diffusion, the previous literature typically considers only the direct (bilateral) trade relationships across countries (e.g., Coe and Helpman, 1995; Keller, 1998; and Comin and Hobijn, 2004). Furthermore, empirical results have often been at odds, perhaps because different measurements have been used to assess trade relationships. For example, Coe and Helpman (1995) use imports to weight foreign R\&D expenditures and find a significant relationship between the import-weighted foreign $R \& D$ expenditures and domestic total factor productivity (TFP), offering evidence of technology diffusion through trade. Using Coe and Helpman's (1995) dataset, Keller (1998) employs the summation of foreign produced $R \& D$ over time rather than import-weighted foreign $R \& D$ to examine the relationship between technology and TFP. In contrast to Coe and Helpman (1995), Keller's (1998) results suggest that knowledge spillovers are independent of trade and are therefore global, rather than local, in nature. Conversely, Keller (2002) argues that trade is concentrated

\footnotetext{
${ }^{1}$ The terms “technology diffusion,” “technology transfer,” and “technology adoption” are often used interchangeably in the literature.

${ }^{2}$ For more detail, see Hoffman (2013) who notes that there is a large literature across multiple disciplines on the links between technology diffusion and both international trade and FDI.

${ }^{3}$ While international trade has received empirical support as an important channel for technology diffusion, the FDI channel has been harder to validate. This may be because, as Keller (2004) observed, testing the FDI channel has been largely restricted to company-level case studies. Section 2 briefly discusses the role of FDI.
} 
because of transportation costs and thus knowledge spillovers are localized. Keller (2004) also concludes that knowledge spillovers are localized because of the nature of technologyunderstanding technology requires interaction between innovator and adopter; trade may provide the needed interaction.

The hypothesis to be tested is that countries that are better-connected on the trade network will have higher technology intensities, which implies greater technology diffusion. We contend that the effect of trade on technology diffusion is not confined to the direct trading partners of the innovator. Once knowledge is received by an innovator's direct trading partners, it can diffuse further to the trading partners of trading partners-i.e., there are spillover effects beyond the initial exchange with an innovating trade partner due to network effects. Thus, the impact of trade would be more accurately assessed by accounting for both direct and indirect trade relationships. This can be done by considering the international trade system as a (weighted) network of trade relationships.

Higher order degrees of "connectivity" can be controlled for when using network indicators that consider the effects of direct (bilateral) trade linkages and their magnitudes as well as the indirect effects that allow countries to gain access a technology even without a direct trade linkage to the innovating country. "Connectivity" on the trade network is quantified by the proximities among countries on the network. For example, it is possible to analyze the dynamics of technology diffusion by considering core-periphery dynamics in which a number of more technologically advanced "core" countries are connected to each other, while countries in the periphery can extract information from the core even without direct connections to it.

Annual bilateral trade data from the NBER-United Nations Trade Data (Feenstra et al., 2005) are used to build a representation of the international trade network, where countries are the nodes of the network and the values of the bilateral trade flows denote the links between them. The trade network data are merged with the Cross-country Historical Adoption of Technology (CHAT) dataset (Comin and Hobijn, 2009) to study technology diffusion dynamics, where both direct and indirect trade linkages on the networks are posited to be the conduits of technology diffusion across countries. The combination of these datasets yields a three-dimensional panel of 145 countries and 24 technologies over the 39-year period from 1962 to 2000. Our central finding is that both direct and indirect network effects of trade appear to play significant roles in technology diffusion. In 
most cases, there is strong and robust evidence that better-connected countries tend to adopt or assimilate (measured by intensity of use) newer and more advanced technologies faster. Interestingly, our dataset includes some technologies for which clear substitutes have emerged; for these, the analysis shows that countries with higher levels of connectivity tend to have much lower levels of adoption of such technologies through time. These two findings together provide strong evidence of the importance of trade in the process of technology diffusion. The latter finding supports the assumptions of quality-ladder models (Aghion and Howitt, 1992) in which older (lower quality) products are continuously replaced by newer (higher quality) products.

The remainder of the paper is organized as follows: Section 2 reviews the relevant literature. Section 3 introduces the trade data and formally defines the trade network. Section 3 describes the technology data and examines technology diffusion on the trade network. Section 4 specifies our empirical methodology and summarizes our major findings. Finally, Section 5 provides some discussions and concludes the paper.

\section{Literature Review}

Our literature review focuses on macroeconomic-level studies. Thus, our review is by no means comprehensive, but rather discusses the works that are most germane to our study. More comprehensive surveys of the extensive literature on technology diffusion are presented in Saggi (2002) and Keller (2004, 2010).

\subsection{Why Is Technology Diffusion Important?}

An important finding of empirical studies of economic growth is that cross-country differences in per capita income can be attributed to differences in TFP, rather than to differences in the levels or initial allocations of factors of production (Prescott, 1998; Hall and Jones, 1999; and Restuccia et al., 2008). ${ }^{4}$ TFP, or the Solow Residual, is a "black box" ${ }^{5}$ that can be interpreted as technological, institutional, cultural, or any other factors besides labor and (physical and human) capital inputs that influence productivity. Since most of these other factors are unobservable, it is

\footnotetext{
${ }^{4}$ Another view is that cross-country differences are due to differences in capital per worker, where capital includes both physical and human capital. Mankiw et al. (1992) is an influential work in this area.

${ }^{5}$ Abramovitz (1956) characterizes the Solow residual as a "measure of our ignorance" about TFP growth.
} 
difficult for economists to quantify their contributions to TFP. However, most economists would agree that technology plays a key role in determining TFP.

Innovation is difficult and costly, but once generated it is non-rival good-it can be used simultaneously by multiple agents without reducing the other's access to it (Romer, 1990). However, as Saggi (2002) points out, non-rivalry does not mean that technology is available at zero cost; technology can only be adopted if an agent who has access to it and is willing to pay the cost of adopting it. Knowledge spillovers reduce the cost of technical change by allowing noninnovators to adopt or imitate the technologies developed by others. Knowledge spillovers are important; Keller (2004, 2010) reports that for most countries, foreign technology account for 90\% or more of domestic productivity growth.

Keller (2004, 2010) notes that international technology diffusion, through its effects on TFP, affects both the distribution and the growth of world incomes. Whether countries' incomes converge over time depends on whether technology diffusion is global or local. A better understanding of technology diffusion therefore provides insights into how less developed countries might catch up with richer ones. Furthermore, stronger cross-country technology diffusion raises the rate at which the world's technology frontier advances. ${ }^{6}$ Thus, it is difficult to overstate the importance of the dynamics of technology diffusion on global economic growth and poverty reduction.

\subsection{Technology Diffusion in Theory}

Theoretical links have been established among technology, technology diffusion channels (primarily trade and FDI), and economic growth. One strand of the literature on technology diffusion investigates the technology diffusion and economic growth linkage, while another strand examines the link between technology diffusion and diffusion channels; a third strand of the literature combines the first two (Eaton and Kortum, 2001). We begin by discussing studies that focus on relationship between technology diffusion and economic growth.

\footnotetext{
${ }^{6}$ Recognizing that technological innovation and adoption of technology are two different phenomena, Nishimizu and Page (1982) present a decomposition of total factor productivity (TFP) change into technology change (shifts in the production frontier) and efficiency change or "catching up" (movements toward the production frontier).
} 
Who benefits from technological progress? Is it the case that technical innovation becomes immediately available everywhere and each country enjoys the same level of technology (Solow, 1956; Mankiw et al., 1992)? Or do countries only improve productivity through their own innovation (Romer, 1990; Aghion and Howitt, 1992)? Eaton and Kortum (1999) argue that reality falls somewhere between these two extremes, with global productivity growth driven by the innovations of a small set of countries and subsequent knowledge spillovers that allow other countries to imitate and adopt the innovations.

A natural starting point for studying technology diffusion is to modify the standard neoclassical growth model by assuming that there is access to new technology and introducing the cost of adopting it. Parente and Prescott (1994) emphasize barriers to technology adoption as a key determinant of differences in per capita income across countries. In their model, although any firm can access the underlying stock of knowledge in the world economy, the cost of such access differs across countries due to differences in legal, regulatory, political, and social factors. Thus in their view, some countries make it inherently more costly for their firms to adopt new technologies and thereby retard the development of the entire economy.

A drawback of Parente and Prescott's (1994) approach, and of the neoclassical growth model in general, is that technological change itself remains unexplained. Without a solid explanation of technological change, it is difficult to explain the diffusion of technology. For this reason, the endogenous growth model has become attractive. Two widely used theories of endogenous growth are the expanding varieties (Romer, 1990) and quality ladders models (Aghion and Howitt, 1992). The former captures the horizontal innovation process, the latter the vertical innovation process. The key difference between these two approaches is that in the varieties model new products do not make old ones obsolete, while in the quality ladders model new products will replace older ones. Barro and Sala-i-Martin (2004) use the varieties model in an empirical study technology diffusion and growth, while the empirical work of Eaton and Kortum (1996) and Howitt (2000) is based on the quality ladders model. Interestingly, Barro and Sala-i-Martin (2004) note that similar results could be obtained from either the varieties or quality ladders models. The key idea is that follower countries tend to catch up with the leaders because the adoption and imitation of new discoveries are cheaper than the development of new technologies. Klenow and Rodriguez-Clare (2005) stress two features shared by both models. The first is that, in steady state, all countries 
grow at the same rate due to technology diffusion. The second is that differences in policies or other country parameters (e.g., diffusion barriers) generate differences in TFP levels rather than in growth rates.

The primary channels for technology diffusion are international trade and FDI through which knowledge is transferred in both embodied and disembodied forms (Helpman, 1997). Traditional theories of trade typically assume that exogenous technical change gives rise to trade because of a comparative advantage provided by locally available technologies. Recent studies have incorporated dynamic relationships and endogenous technical change. Thus, while technology can affect trade patterns, international trade and FDI also affect differences in technology by serving as channels for diffusion (Grossman and Helpman, 1995). As noted in Helpman (1997), trade and FDI contribute to technological progress by making available the processes, products, and services that embody foreign knowledge, thus providing knowledge that would otherwise be unavailable or very costly.

\subsection{Technology Diffusion in Practice}

Technology and its diffusion are not directly measurable, so they must be quantified by observable proxies. As discussed in Keller (2004, 2010), empirical studies use three indirect measures to proxy technology—R\&D (an input measure of technology), patents (an output measure of technology), and productivity (an outcomes measure of technology). Technology diffusion can transpire directly through market transactions or indirectly through spillovers. Market transactions typically involve royalty payments for the use of patents, licenses, and copyrights. Although data on market transactions is available for most industrial economies, many economists believe that most international technology diffusion occurs not through market transactions but rather through spillovers, with international trade and FDI, among other factors, serving as conduits for these spillovers.

A common hypothesis is that technology diffusion is shaped by geography (Keller, 2010) diffusion is a form of "contagion," with the probability of transmission from one party to another decreasing with distance. Two implications of the hypothesis are that technology diffusion within countries is stronger than across countries and that technology diffusion weakens as distance increases. The evidence generally supports these hypotheses. For example, Eaton and Kortum 
(1999) find that within the Group of 5 (G5) countries (UK, France, Germany, Japan, and US), the rate of domestic technology diffusion is much higher than for non-G5 countries. Based on data for 14 OECD countries for 1970-1995, Keller (2002) finds a statistically significant negative relationship between the distance from the G-5 countries and the technology diffusion of their innovations to the other nine countries.

While geography appears to matter, the estimated geographic effects may be due to unobserved heterogeneity across countries. In the remainder of this section we address heterogeneity by reviewing some empirical studies that focus on specific diffusion channels.

International trade is one of the most frequently mentioned channels of technology diffusion. Trade can be further divided into the roles played by imports and exports. ${ }^{7}$ To improve productivity and enhance competitiveness, firms/countries can "learn-by-exporting." Case studies of the export success of a number of East Asian countries in the 1960s emphasize learning-by-exporting effects (Rhee et al., 1984). Based on a non-parametric dynamic model of productivity, Ferrier et al. (1998) find that Yugoslav co-operatives that adopted an export orientation performed better than those that did not. More recently, De Loecker (2010) finds substantial firm-level productivity gains from entering export markets. As for imports, Coe and Helpman (1995) find positive and significant effects of import-share-weighted foreign R\&D stock on domestic TFP for a group of OECD countries. However, as is the case with many pioneering works, Coe and Helpman's (1995) results have been challenged. For instance, Keller (1998) uses randomly assigned import shares to construct foreign R\&D stock and obtains better results than Coe and Helpman (1995). Furthermore, instead of using overall trade as in Coe and Helpman (1995), Xu and Wang (1999) find that technology diffusion is specifically associated with the trade of differentiated capital goods.

FDI as a channel of technology diffusion is also the subject of much research, with a distinction often made between inward and outward FDI. For example, a case study of Intel's FDI into Costa Rica provides evidence that a major high-tech company can trigger enormous technical change in a relatively small country (Larrain et al., 2000). As another example, Iacovone et al. (2009) report

\footnotetext{
${ }^{7}$ Theoretically, technology may be diffused through both importing and exporting. Empirical evidence strongly supports the importing channel, while the exporting channel is relatively harder to justify. See Keller $(2004,2010)$ for a detailed survey.
} 
that when Walmart brought its centralized distribution system, use of palettes, and other supply chain modernizations to its Mexican subsidiary Walmex, the innovations quickly diffused among other major retail chains in Mexico. To draw more general implications than can be provided by case studies, Xu (2000) uses the Bureau of Economic Analysis data on US outward FDI into 40 countries over almost 30 years and finds a positive relation between FDI and domestic productivity growth, which is stronger in developed countries than in less developed ones. Xu and Wang (2000) examine the effects of both trade and FDI on technology diffusion; they conclude that while trade in capital goods and outward FDI are associated with the diffusion of technology, inward FDI is not.

\subsection{Network Effects on Technology Diffusion}

As an empirical study of the trade network's effect on technology diffusion, this paper belongs to the literature pioneered by Coe and Helpman (1995). Before discussing our contributions, it is worth noting two potential drawbacks of Coe and Helpman (1995). First, they only consider direct bilateral trade. However, technology may also spread through indirect trade relationships (i.e., network effects). Second, there is a potential endogeneity problem associated with their model specification, an issue that will be discussed in more detail below.

To illustrate how technology diffusion can occur in the absence of direct linkages, assume that there are only three countries in the world - A, B, and C. Suppose that A only trades with B, while B trades with both A and C (see Figure 1). In Coe and Helpman's (1995) model, the lack of bilateral trade between A and C disallows the diffusion of A's technology C. However, because A trades with B, and B trades with C, A indirectly "trades" with C and thus technology may diffuse from A to $\mathrm{C}$ through B; i.e., the network effects of trade may result in "contagion."

Recently, the literature has given more attention to the indirect trade effects. For example, Lumenga-Neso et al. (2005) make a distinction between "produced” R\&D and "available” R\&D. "Produced" R\&D resides in the country that created it, but can be transmitted to other countries through direct trade; once transmitted to another country it becomes part of the importer's "available” knowledge. “Available” knowledge can spillover to any country—obviating the need for a direct trade link between the knowledge creator and potential knowledge recipients; i.e., once knowledge flows from one country to another, it is indirectly available to other countries. 
Lumenga-Neso et al. (2005) find that the indirect trade effects on domestic TFP are at least as important as the direct bilateral trade effects. Franco et al. (2011) argue that while geographic distance between countries affects diffusion, the "economic distance" ("trade rounds" in their paper) between them also matters. Using bilateral import data, Franco et al. (2011) build a countryby-country "average propagation length" matrix and then use it to weight each country's domestic $R \& D$ expenditures to obtain the "relative stock" of R\&D available in each country. The relative stock of R\&D includes foreign $R \& D$ accessed through both direct and indirect trade. Comparing estimation results across models that include and exclude the indirect effect of trade, Franco et al. (2011) conclude that the indirect effects of trade play a significant role in determining domestic TFP. While these studies focus on the trade's indirect effects, there are at least two differences visà-vis our study. First, the previous studies are based on calculating the weighted foreign R\&D stock, while ours is based on an explicit network indicator to capture the interconnectedness between countries. Second, we use specific technologies rather than TFP as the dependent variable, which should mitigate endogeneity concerns.

Network analysis is well suited to identifying the indirect trade effects. Briefly speaking, a network is a description of the pattern of connections between a collection of nodes (or vertices) and links (or edges) (Watts, 2003; Newman, 2010). Networks differ in their structures; indicators such as shortest paths, centrality, and clustering coefficients characterize their structures (Newman, 2010). Network analysis has been widely applied in a diverse set of disciplines such as information technology, biology, and sociology to study the interconnectedness of nodes in a network (Watts, 2003; Newman, 2010). Within the economics literature, network analysis has received growing attention and has been used to explain economic development, economic integration, and financial contagion (Reyes et al., 2008; Kali and Reyes, 2010; Schiavo et al., 2010) at the macro level, and the importance of "network externalities" (Shapiro and Varian, 1998; Goyal, 2007) at the micro level, among other phenomena.

Previous studies have noted the role that geographical distance plays in technology diffusion. ${ }^{8}$ Recently, the role of "economic distance" has been considered. This paper also considers the role of "economic distance" by constructing network indicators to test how trade network distance

\footnotetext{
${ }^{8}$ Comin et al. (2012) argue that the requisite knowledge to adopt technology is often acquired through interactions between agents. They find strong empirical evidence that the interactions are influenced by geography.
} 
affects the diffusion of specific technologies. Importantly, while geographical distance is fixed over time, network distance displays rich dynamics over time. Thus, network analysis provides a novel and important tool for exploring technology diffusion.

Network effects measure the "connectivity" structure of a network based on both direct and indirect links between nodes. We use the shortest paths algorithm to calculate the average geodesic distance-a commonly used measure of connectedness-between countries in the trade network. This measure is then included as a regressor in an econometric model to examine its effect on technology diffusion. ${ }^{9}$ It is important to note that the direct path between two nodes is not necessarily the shortest path between them; instead, the shortest path may be an indirect one that runs through intermediate countries.

As noted above, endogeneity is a potential problem with econometric models that specify domestic TFP (an outcome measure of technology) as the dependent variable while using domestic and foreign R\&D stocks (input measures of technology) as independent variables. Since a country with higher productivity will likely engage in more R\&D activities, the causal effects, if any, could go from dependent variable to independent variables. One way to address this problem is to use direct measures of technology. Direct measures are available through Comin and Hobijn's (2004) pioneering work on historical technology adoption data. The Cross-country Historical Adoption of Technology (CHAT) dataset (Comin and Hobijn, 2009) contains direct measures of diffusion for 104 technologies across more than 150 countries. Examining specific technologies in the CHAT dataset, Comin and Hobijn (2004) find that trade openness, human capital, and institutions are all determinants of the speed of technology adoption. The issue of endogeneity is alleviated because it is reasonable to assume that the use of a specific technology as a dependent variable should not reversely affect aggregate control variables such as GDP, trade openness, and human capital.

\section{Trade Network and Technology Data}

In our empirical analysis we use the bilateral trade flows reported in the NBER-United Nations Trade Data (Feenstra et al., 2005) to construct the trade network and combine it with the CHAT

\footnotetext{
${ }^{9}$ Actually, what we find is the significant impact of the average geodesic distance on country's technology intensity level. The implicit assumption here is that technology intensity is mainly the result of technology diffusion.
} 
dataset (Comin and Hobijn, 2009) on the diffusion of technologies over time. After merging the international trade network and technology datasets, our sample includes data on 24 technologies and 145 countries over the period 1962-2000.

The trade database covers the years 1962-2000 and 203 countries and areas. ${ }^{10}$ The data are organized in an $N \times N$ bilateral trade matrix $B$ for each year, where $N=203$ and each cell $B_{i, j}$ represents the trade flows from country $j$ to country $i$, with $B_{i, i}=0$. Reported imports are used to build the bilateral trade flows, where the imports of country $i$ from country $j$ correspond to the exports of country $j$ to $i .{ }^{11} \mathrm{~A}$ total trade approach is used to compute the total trade (symmetric) matrix $W=B+B^{\prime}$, where $W_{i, j}=B_{i, j}+B_{j, i}=W_{j, i}$.

The technology measures in the CHAT dataset are converted into intensity measures to assure that cross-country comparisons are meaningful. ${ }^{12}$ Table 1 contains descriptions of the intensity variables for 24 technologies we investigate. With the exception of three "general" technologies (computers, electricity production, and internet usage), the CHAT dataset sorts technologies into 8 industries-agriculture, finance, health, steel, telecommunications, textiles, tourism, and transportation. Agriculture, finance, and tourism are excluded from our analysis because the sizes and natures of these industries differ substantially across countries and it is difficult to define appropriate intensity measures for these technologies.

\section{[Insert Table 1 here]}

To capture both the direct and indirect effects of trade on technology diffusion, the "economic distance" between counties on the trade network must be measured. For each country, distance in

\footnotetext{
${ }^{10}$ To account for historical unification or fragmentation of countries, we always consider the geographically larger economy as the only predecessor or the only successor so that the methodology is consistent with the technology data. For example, we consider Russia as the only successor of Former USSR and all other Former USSR countries as completely new countries after 1991. Also, since the former Federal Republic of Germany is geographically larger than the former German Democratic Republic, we consider the Federal Republic of Germany as the only predecessor of Germany before 1991. See Table A1 in the Appendix for information on how the trade data were merged.

${ }^{11}$ Arguably, data reported by importing countries is more reliable and complete than the data reported by exporting countries. This is, in part, because tariffs are often collected on imports.

${ }^{12}$ Following Comin and Hobijn (2004), the following intensity measures are computed: 1) percentages of population for the health industry, e.g., percent of children aged 12-23 months who received a DPT immunization before the age of one year; 2) production shares for the steel, textiles, and transportation industries, e.g., fraction of the total crude steel produced in blast oxygen furnaces; 3 ) volume/amount per unit of real GDP measures for the steel and transportation industries; e.g., aviation cargo (ton-kilometers) per unit of real GDP; 4) per capita measures for the telecommunications and transportation industries, e.g., televisions per capita.
} 
the trade network is measured by average geodesic distance-the mean of the shortest path (number of links or relations) between a country and all other countries in the network. A country's closeness centrality (Jackson, 2010; Newman, 2010) is the reciprocal of the average geodesic distance: 13

$$
C_{i}=\frac{N-1}{\sum_{j \neq i} d(i, j)}
$$

where $N$ is the number of countries in the trade network and $d(i, j)$ is the shortest distance between countries $i$ and $j .{ }^{14}$ Closeness centrality measures how strongly nodes interact with one another. The larger the value of $\mathrm{Ci}$ the shorter the average distance from the country to any other country on the network (i.e., there are fewer intermediaries between them), and therefore the more likely it is to transmit knowledge spillovers to other countries. For an unweighted network, ${ }^{15}$ the geodesic distance is simply the minimum number of links connecting any two nodes. For a weighted network, measuring geodesic distance is more complicated because links are heterogeneous. Dijkstra (1959) solves the geodesic distance measurement problem for a weighted network by considering costs as the weights. ${ }^{16}$ The solution is to find the path with the lowest costs. In most networks, however, the weights measure the strengths, rather than the costs, of the links. ${ }^{17}$ For the technology diffusion network, the weights (strengths) can be divided into two parts-bilateral trade volume and foreign technology intensity. First, greater bilateral trade volume leads to stronger trade relationships and hence easier access to technology. Second, for a given country in the network, the technology intensity levels of its trading partners also matter because the higher

\footnotetext{
13 There are a number of node centrality measures. In addition to closeness centrality there are degree centrality (the number of links the node has) and betweenness centrality (the number of the shortest paths crossing the node). See Jackson (2010) and Newman (2010) for details.

14 There are other definitions of closeness centrality; for example, some define closeness centrality as the average geodesic distance (the reciprocal of the measure used here).

${ }^{15}$ An unweighted network is also called binary because the links are homogeneous and merely represent the presence or not for a certain kind of relationship. A weighted network would take into account other characteristics of the links, such as volume, frequency, costs, etc., depending on the context.

${ }^{16}$ For example, in a transportation network, the weights may be the traffic volume. The higher the traffic volume, the more costly it is to get through that link.

${ }^{17}$ For example, in a social network, the weights may be the count of interactions between any two people. The more frequent interactions, the stronger the link and therefore the less costly to communicate with each other.
} 
it's trading partners' technology intensities, the greater is the likelihood that technology will diffuse to it through trade. ${ }^{18}$

Let $Y_{j}$ be country $j$ 's technology intensity. Combining this with $W_{i, j}$, the bilateral trade volume between countries $i$ and $j$, we define the weight of the link between countries $j$ and $i$ as $Y_{j} \cdot W_{i, j}$. The greater the value of $Y_{j} \cdot W_{i, j}$, the less costly it is for technology to diffuse from $j$ to $i$.

Following Newman (2001) and Brandes (2001), Dijkstra’s (1959) algorithm for calculating geodesic distance is implemented by defining costs as the reciprocals of the weights. To allow for a wider range of specifications, we follow Opsahl et al. (2010) and introduce a tunable parameter, $\alpha$, in the measure of direct path length. As a result, we define a direct path length matrix, $P^{d i r}$, where each element $P_{i, j}^{d i r}$ is the direct path length from country $j$ (the country with a technology) to country $i$, (the country to which the technology may diffuse) and is calculated as:

$$
P_{i, j}^{d i r}=\frac{1}{\left(Y_{j} W_{i, j}\right)^{\alpha}}
$$

where $\alpha \geq 0 .{ }^{19}$ The matrix $P^{d i r}$ is asymmetric because $P_{i, j}^{d i r}$ and $P_{j, i}^{d i r}$ are only equal if the two countries have exactly the same technology intensity, which is unlikely to be the case. As in Newman (2001), Brandes (2001), and Opsahl et al. (2010), the indirect path length is calculated by summing the direct paths that link countries $i$ and $j$ :

$$
P_{i, j}^{\text {indir }}=P_{i, h}^{\text {dir }}+\cdots+P_{g, j}^{d i r}=\frac{1}{\left(Y_{h} W_{i, h}\right)^{\alpha}}+\cdots+\frac{1}{\left(Y_{j} W_{g, j}\right)^{\alpha}}
$$

where $\alpha \geq 0$ and $h, \ldots, g$ are the intermediate countries between $i$ and $j$.

Figure 1 illustrates the notions of direct and indirect path lengths for the case of three countries, A, B, and C, which trade with one another. Notice that the link between countries is both weighted (link width) and directed (arrow). The direct path length from $\mathrm{C}$ to A is $P_{A, C}^{d i r}$, while the indirect

\footnotetext{
${ }^{18}$ It is this second aspect that makes the network directed; i.e., asymmetric. For example, say, A trades with B but only A has the technology in question. Then there is a link pointing from A to B, but no (directed) link from B to A.

${ }^{19}$ The tunable parameter "balances" the influence of the number of connections a node has with other nodes and the strength of those connections. The original form of Dijkstra's (1959) algorithm for weighted networks has $\alpha=1$. When $\alpha=0$, the network is unweighted; when $0<\alpha<1$, more costs are associated with a given number of intermediate links; and when $\alpha>1$ lower costs are associated with a given number of intermediate links. In Section 4 , we run benchmark regressions using $\alpha=1$. The robustness of results is examined using $\alpha=0.5$ and $\alpha=1.5$.
} 
path length from $\mathrm{C}$ to $\mathrm{A}$ is $P_{A, C}^{\text {indir }}=P_{A, B}^{\text {dir }}+P_{B, C}^{\text {dir }}$ with country $\mathrm{B}$ serving as an intermediary between $\mathrm{A}$ and $\mathrm{C}$. As noted above, the indirect path $P_{A, C}^{\text {indir }}$ may be shorter than the direct path $P_{A, C}^{\text {dir }}$

\section{[Insert Figure 1 here]}

Let $\boldsymbol{P}_{i, j}^{\text {indir }}$ be the set of all possible indirect paths from country $j$ to country $i$. Then the geodesic distance (i.e., the shortest path) from $j$ to $i$ is:

$$
S_{i, j}=\min \left\{P_{i, j}^{\text {dir }}, \boldsymbol{P}_{i, j}^{\text {indir }}\right\}
$$

Finally, the average geodesic distance to all $n$ technology-available trading partners for country $i$ is given by:

$$
D_{i}=\frac{\sum_{j=1}^{n} s_{i, j}}{n}
$$

Comin and Hobijn (2004) use the trade-share-weighted average of technology intensity level of adoption of trading partners as a control variable:

$$
T W_{i}=\frac{\sum_{j=1}^{m} Y_{j} W_{i, j}}{\sum_{j=1}^{m} W_{i, j}}
$$

where $m$ is the number of countries with which country $i$ has bilateral trade relationships. Note that the trade shares in equation (6) are based only on bilateral trade; hence, network effects are ignored. To control for the direct effects of trade on technology diffusion, we include $T W_{i}$ as a regressor in our econometric analysis.

Before proceeding to the econometric model and empirical results, it is worth briefly discussing summary statistics of the technology data, the technology diffusion networks, and the average geodesic distance measures. Figure 2 shows plots of the cross-country average technology level over time. As can be seen, most technologies have an upward trend over time, indicating that the level of adoption has been increasing. The intensity levels for "CableTV," "Newspaper," and "Railway_passenger" are roughly constant at the end of the sample period, suggesting that they are mature technologies. Finally, some technologies_- “Steel_OHF," “Mail,” “Telegram,” “Textile_artificial," and "Railway_cargo"—show clear patterns of decline in recent years, 
suggesting that they are becoming obsolete. To further explore whether a technology is becoming obsolete we examine fitted kernel density distribution functions for selected years. To illustrate, we use “Cellphone” as a typical new technology and "Telegram” as a typical obsolete technology. The top row of Figure 4 contains the kernel functions for log measures of "Cellphone" and “Telegram.” Clearly, the mode of "Cellphone” has moved to the right along the horizontal axis, which confirms that "Cellphone" is a relatively new technology that continues to diffuse over time. In contrast, the distribution of "Telegram" has shifted leftward over time, suggesting that it is becoming an obsolete technology. A similar conclusion can be drawn by comparing the growth rate distributions for these two technologies, which are illustrated in the bottom row of Figure 3.

\section{[Insert Figures 3-4 here]}

A simple way to check the dynamics of the technology diffusion networks is to calculate network density over time. Let $q_{k, t}$ be the number of existing links for year $t$ and technology $k$ and $M=$ 145 be the number of countries in the trade-technology-combined data. The network density in year $t$ for technology $k$ is:

$$
\varphi_{k, t}=\frac{q_{k, t}}{M(M-1)}
$$

where $M(M-1)$ is the total number of possible links since the network is directed. Figure 4 illustrates the network densities for each technology over time. The obsolete technologies "Mail” and "Telegram" show a clear decline in network density, while relatively new technologies such as immunization technologies, “Internet”, and "PC”, have increasing densities over time. However, because the presence of a link requires both the presence of (foreign) technology and the presence of bilateral trade, the density fluctuates a lot for transportation technologies, some telecommunication technologies, and "Electricity."

Table 2 contains summary statistics on indirect paths. The first column lists the 24 technologies analyzed. Column 2 reports the average percentage of all shortest paths that are indirect paths, $\frac{\text { indir }}{\text { total }}$. Column 3, $\frac{\text { indir_replace }}{\text { dir_available }}$, provides the average percentage of direct paths that are replaced by indirect shortest paths. Finally, the last column, $1-\frac{d i r_{\text {available }}}{\text { total }}$, reports the average percentage of indirect shortest paths for which there is no direct path between two countries. As can be seen from the values in Columns 2 and 3, the shortest paths are dominated by indirect paths. Moreover, 
a significant portion of the shortest paths are cases for which two nodes are not directly linked to each other but are only connected through intermediate nodes (see Column 4).

\section{[Insert Table 2 here]}

\section{Empirical Model, Results, and Robustness Checks}

A country-fixed-effects model with the tuning parameter set at $\alpha=1$ is the benchmark we use to test the hypothesis that countries adopt new technologies more quickly the more closely connected through trade they are to prior adopters: ${ }^{20}$

$$
Y_{i t}^{k}=\beta_{1 i} C_{i}+\beta_{2} D_{i t}^{k}+\beta_{3} R G D P_{i t}+\beta_{4} \text { Openness }_{i t}+\beta_{5} T W_{i t}^{k}+\epsilon_{i t}^{k} .
$$

The dependent variable, $Y_{i t}^{k}$, is the intensity level of technology $k$ for country $i$ in year $t$ and $D_{i t}$, the regressor of primary interest, is the network effects indicator measured by average geodesic distance. Control variables include country-specific fixed effects, $C_{i}$, real GDP per capita $\left(R G D P_{i t}\right)$, the ratio of nominal trade volume to nominal GDP (Openness $\left.i t\right)$, and the trade-shareweighted average of technology intensity levels of trading partners $\left(T W_{i t}^{k}\right) \cdot{ }^{21}$ The coefficient of on $D$ measures the impact of the average geodesic distance on the level of technology adoption. If being better connected on the trade enhances the technology diffusion process, $D$ and $Y$ would be negatively related. Summary statistics of the distance variables used in the benchmark regressions are reported in Table 3.

\section{[Insert Table 3 here]}

We estimate equation (8) separately for each of the 24 technologies in our dataset. This allows the estimated coefficients to vary across technologies, reflecting the heterogeneous impacts that

\footnotetext{
${ }^{20}$ This specification can be viewed as an extension of Comin and Hobijn (2004).

${ }^{21} R G D P$ is calculated based on the CHAT dataset. Openness is extracted from the Penn World Table 7.0 (Heston et al., 2011). Another possible control variable is education. Increases in education enhance the capacity to absorb knowledge spillovers. Common proxies for education include the primary school enrollment and the secondary school enrollment rates. Unfortunately, data on school enrollment is not available in many cases. Therefore, to ensure a large number of observations, and to avoid problems of multicollinearity, we don't include the education (human capital) variables in the regression models reported in the body of the text. Regression results for models with education variables are reported in Table A6 and A6 in the Appendix; qualitatively, the results don't differ across the two specifications.
} 
average geodesic distance and the control variables likely have on the diffusion of different technologies. Regression results are reported in Table $4 .{ }^{22}$

\section{[Insert Table 4 here]}

Our central findings can be summarized as follows:

1) The estimated coefficient on the distance variable, $D$, is statistically significant for 22 of the 24 technologies. This supports our hypothesis that stronger linkages, both direct and indirect, on the trade network affect technology diffusion. The estimated coefficient is statistically significantly negative for 17 of the 24 technologies examined. For example, the negative relationship between technology adoption and distance is well supported in the health industry, as both types of immunization (DPT and measles) have statistically significant negative signs for $\beta_{2}{ }^{23}$

2) For older ("obsolete") technologies, for which clear substitutes have emerged, the estimated coefficients on $D$ are either statistically significantly positive (5 technologies"CableTV," "Mail," and "Telegram” in the telecommunications industry, and "Railway" (both passenger and cargo) in the transportation industry) or insignificant (2 technologies"BOF" in the steel industry and "Textile_artificial”). This suggests that better connected countries can more easily adopt newer technologies to replace those that are becoming obsolete.

Our findings provide strong evidence of the importance of trade in the process of technology diffusion—-better connected countries tend to perform better by more quickly adopting relatively newer technologies and by casting away older, “obsolete” technologies.

As noted earlier, there is a potential endogeneity problem in Coe and Helpman (1995). As argued above, it's reasonable to assume that there isn't reverse causality between the adoption of specific technologies, the dependent variable, and the macroeconomic regressors RGDP and Openness.

\footnotetext{
${ }^{22}$ We test whether serial correlation is present in our panel data model (Wooldridge, 2002; Drukker, 2003). With the exception of "Autoloom," serial correlation is present. As a result, we use Arellano's (1987) serial correlation/heteroskedasticity robust estimator to obtain standard errors.

${ }^{23}$ The other technologies with statistically significantly negative relationships between trade and adoption are "Steel_EAF," "Cellphone,” "Newspaper," "Radio," "Telephone,” and "TV” in the telecommunications industry, "Textile_synthetic" in the textile industry, "Aviation" and "Car" in the transportation industry, as well as the general technologies "Electricity" and "Internet."
} 
However, there is a potential endogeneity bias with respect to the regressors $D$ and $T W$. In particular, the technology intensity of country $i$ may enter the construction of $D$ and $T W$ in other countries. Like Comin et al. (2012), we argue that, even if endogeneity bias is present, it is likely negligible because our sample contains a large number of countries. Thus, the effect of a single country's technology intensity has a relatively small effect on the sizes of $D$ and $T W$ for other countries since these two measures are weighted averages based on all the countries in the dataset.

Nonetheless, we examine potential endogeneity bias in our model. The diffusion of technology is not instantaneous; therefore, we re-estimated equation (8) after replacing the contemporaneous values of $D$ and $T W$ with their one-period lagged values. Results based on the lagged variables, reported in the Appendix, indicate that both the signs and significances of the estimated coefficients on $D$ are quite robust.

As a further robustness check, equation (8) was re-estimated using the values of average geodesic distance generated using $\alpha=0.5$ and $\alpha=1.5$ as the values of the tuning parameter. The average number of intermediate links is higher when $\alpha=1.5$ (the number of intermediate links matters less), and is lower when $\alpha=0.5$ (the number of intermediate links matters more). ${ }^{24}$ Estimation results based on $\alpha=0.5$ and $\alpha=1.5$ are reported in Tables A3 and A4, respectively, in the Appendix. With three exception, both the signs and significance levels of the estimated coefficients on $D$ are very robust to the value of the tuning parameter. ${ }^{25,26}$

Finally, equation (8) was augmented with the regressors $G 7$ and $G 7^{*} D$, where $G 7$ is a dummy variable for the Group of 7 (G7) countries (US, UK, Japan, Germany, Canada, France, and Italy). The G7 countries are arguably the most innovative in the world. ${ }^{27}$ Interestingly, $G 7 * D$ does not

\footnotetext{
${ }^{24}$ See Table A2 in the Appendix for the average number of intermediate links for each technology based on these alternative values of $\alpha$.

${ }^{25}$ The exceptions are "Steel_BOF," "Steel_OHF," and “Autoloom.” For "Steel_BOF” the coefficient on $D$ remains insignificantly negative when $\alpha=1.5$, but the coefficient is statistically significantly negative when $\alpha=0.5$.

"Steel_OHF" has negative and significant coefficients on $D$ when $\alpha=1$ and $\alpha=1.5$, but an insignificant positive coefficient when $\alpha=0.5$. Finally, "Autoloom" has negative and significant coefficients on $D$ when $\alpha=1$ or $\alpha=1.5$, but an insignificant negative coefficient on $D$ when $\alpha=0.5$.

${ }^{26}$ For the control variables, results with $\alpha=1.5$ is more robust than those with $\alpha=0.5$. I.e., results are more robust when the number of intermediate links matters less (i.e., when more indirect paths are identified as the geodesic distances).

${ }^{27}$ In recent years, the contribution to global innovation from other advanced economies and developing countries, such as China and India, has increased rapidly. However, since our sample is restricted within 1962-2000, the G7 is still a fairly informative representation of the world technological frontier back to that time.
} 
matter for most technologies (see Table A5 in the Appendix). However, when it does matter, it is significantly positive and offsets the negative impact of $D$ (except for the steel industry). That is, compared with the "imitators," the "innovators" tend to have higher technology intensity level the farther away they are from the rest of the network. This may be the case for two reasons. First, this may be the result of "protection" efforts by the innovators. Innovators have strong incentives to protect their technological advances from imitators so that they can extract greater economic benefits from their R\&D efforts. As a consequence, innovators may tend to develop and intensify technologies for which they are farther away from the potential imitators. Second, it means that better connectedness would benefit imitators, which also fits our intuition.

\section{Concluding Remarks}

Theoretically, trade serves as a major channel of technology diffusion; empirical evidence supports the theory. To empirically test the effects of trade on technology diffusion, previous literature typically considers the direct (bilateral) trade effects on the indirect measures of technologies (TFP). We argue that the impact of trade on technology diffusion would be more accurately measured when the indirect network effects are also taken into account and when direct, rather than indirect, measures of technology diffusion are used. In the weighted trade network, technology can be diffused bilaterally between two countries as well as through network effects (i.e., indirectly through trade with intermediate countries). To examine network effects we include an indicator of network structure, average geodesic distance, in our empirical analysis. Our results suggests that the network effects of trade play a significant role in technology diffusion. That is, better-connectedness on the trade network increases the rates at which countries adopt newer technologies and cast away older, perhaps obsolete, technologies for which clear substitutes have emerged. The latter finding is consistent with quality-ladder models (Aghion and Howitt, 1992) in which older (lower quality) products are continually replaced by newer (higher quality) products. 


\section{References}

Abramovitz, M. (1956), “Resource and Output Trends in the United States since 1870,” American Economic Review, 46(2), 5-23.

Aghion, P. and Howitt, P. (1992), “A Model of Growth through Creative Destruction,” Econometrica, 60(2), 323-351.

Arellano, M. (1987), “Practitioner’s Corner: Computing Robust Standard Errors for Within-groups Estimators,” Oxford Bulletin of Economics and Statistics, 49(4), 431-443.

Barro, R. and Sala-i-Martin, X. (2004), Economic Growth, MIT Press, Cambridge, MA.

Brandes, U. (2001), “A Faster Algorithm for Betweenness Centrality,” Journal of Mathematical Sociology, 25(2), 163-177.

Coe, D. and Helpman, E. (1995), “International R\&D Spillovers,” European Economic Review, 39(5), 859-887.

Comin, D., Dmitriev, M. and Rossi-Hansberg, E. (2012), “The Spatial Diffusion of Technology,” NBER Working Paper No. 18534.

Comin, D. and Hobijn, B. (2004), “Cross-Country Technology Adoption: Making the Theories Face the Facts,” Journal of Monetary Economics, 51(1), 39-83.

Comin, D. and Hobijn, B (2009), “The CHAT Dataset,” NBER Working Paper No. 15319.

De Loecker, J. (2010), “A Note on Detecting Learning by Exporting,” NBER Working Paper No. 16548 .

Dijkstra, E. W. (1959), “A Note on Two Problems in Connexion with Graphs,” Numerische Mathematik, 1, 269-271.

Drukker, D. (2003), “Testing for Serial Correlation in Linear Panel-Data Models,” The Stata Journal, 3(2), 168-177.

Eaton, J. and Kortum, S. (1996), “Trade in Ideas: Patenting and Productivity in the OECD,” Journal of International Economics, 40(3-4), 251-278. 
Eaton, J. and Kortum, S. (1999), “International Technology Diffusion: Theory and Measurement,” International Economic Review, 40(3), 537-570.

Eaton, J. and Kortum, S. (2001), "Technology, Trade, and Growth: A Unified Framework," European Economic Review, 45(4-6), 742-755.

Feenstra, R., Lipsey, R., Deng, H., Ma, A., and Mo, H. (2005), “World Trade Flows: 1962-2000,” NBER Working Paper No. 11040.

Ferrier, G.D., Klinedinst, M., and Linvill, C.B. (1998), "Static and Dynamic Productivity among Yugoslav Enterprises: Components and Correlates,” Journal of Comparative Economics, 26(4), 805-821.

Franco, C., Montresor, S., and Marzetti, G. (2011), “On Indirect Trade-Related R\&D Spillovers: The 'Average Propagation Length' of Foreign R\&D,” Structural Change and Economic Dynamics, 22(3), 227-237.

Goyal, S. (2007), Connections: An Introduction to the Economics of Networks, Princeton University Press.

Grossman, G. and Helpman, E. (1995), “Technology and Trade,” in Handbook of International Economics vol. 3, Grossman, G. and Rogoff, K., eds, North Holland Press, Amsterdam.

Hall, R. and Jones, C. (1999), "Why Do Some Countries Produce So Much More Output per Worker than Others?,” Quarterly Journal of Economics, 114(1), 83-116.

Helpman, E. (1997), “R\&D and Productivity: The International Connection,” NBER Working Paper No. 6101.

Heston, A., Summers, R., and Aten, B. (2011), Penn World Table Version 7.0, Center for International Comparisons of Production, Income and Prices, University of Pennsylvania.

Hofmann, Patricia (2013), The Impact of International Trade and FDI on Economic Growth and Technological Change (Springer-Verlag: Berlin Heidelberg).

Howitt, P. (2000), "Endogenous Growth and Cross-Country Income Differences,” American Economic Review, 90(4), 829-846. 
Iacovone, L., Javorcik, B., Keller, W., and Tybout, J. (2009), "Walmart in Mexico: The Impact of FDI on Innovation and Industry Productivity,” Mimeo, University of Colorado.

Jackson, M (2010), Social and Economic Networks, Princeton University Press.

Kali, R. and Reyes, J. (2010), "Financial Contagion on the International Trade Network," Economic Inquiry, 48(8), 1072-1101.

Keller, W. (1998), “Are International R\&D Spillovers Trade-Related? Analyzing Spillovers among Randomly Matched Trade Partners,” European Economic Review, 42(8), 1469-1481.

Keller, W. (2002), “Geographic Localization of International Technology Diffusion,” American Economic Review, 92(1), 120-142.

Keller, W. (2004), “International Technology Diffusion,” Journal of Economic Literature, 42(3), 752-782.

Keller, W. (2010), “International Trade, Foreign Direct Investment, and Technology Spillovers,” Handbook of the Economics of Innovation, 2, 793-829.

Klenow, P. and Rodriguez-Clare, A. (2005), "Externalities and Growth,” in Handbook of Economic Growth vol. 1, Aghion, P. and Durlauf, S., eds, North Holland Press, Amsterdam.

Larrain, F., Lopez-Calva, L., and Rodriguez-Clare, A. (2000), “Intel: A Case Study of Foreign Direct Investment in Central America,” Working Paper No. 58, Center for International Development at Harvard University.

Lumenga-Neso, O., Olarreaga, M., and Schiff, M. (2005), “On 'Indirect’ Trade-Related R\&D Spillovers,” European Economic Review, 49(7), 1785-1798.

Mankiw, N., Romer, D. and Weil, D. (1992), “A Contribution to the Empirics of Economic Growth,” Quarterly Journal of Economics, 107(2), 407-437.

Newman, M. E. J. (2001), “Scientific Collaboration Networks. II. Shortest Paths, Weighted Networks, and Centrality,” Physical Review E, 64, 016132.

Newman, M. E. J. (2010), Networks: An Introduction, Oxford University Press. 
Nishimizu, M. and Page Jr., J.M. (1982), “Total Factor Productivity Growth, Technological Progress and Technical Efficiency Change: Dimensions of Productivity Change in Yugoslavia, 1965-1978,” Economic Journal, 92(368), 920-936.

Opsahl, T., Agneessens, F., and Skvoretz, J. (2010), "Node Centrality in Weighted Networks: Generalizing Degree and Shortest Paths,” Social Networks, 32(3), 245-251.

Parente, S. and Prescott, E. (1994), “Barriers to Technology Adoption and Development,” Journal of Political Economy, 102(2), 298-321.

Prescott, E. (1998), “Needed: A Theory of Total Factor Productivity,” International Economic Review, 39(3), 525-551.

Restuccia, D., Yang, D. and Zhu, X. (2008), “Agriculture and Aggregate Productivity: A Quantitative Cross-Country Analysis,” Journal of Monetary Economics, 55(2), 234-250.

Reyes, J., Schiavo, S., and Fagiolo, G. (2008), “Assessing the Evolution of International Economic Integration Using Random Walk Betweenness Centrality: The Cases of East Asia and Latin America,” Advances in Complex Systems, 1(5), 685-702.

Rhee, Y., Ross-Larson, B., and Pursell, G. (1984), Korea's Competitive Edge: Managing the Entry into World Markets, Johns Hopkins University Press, Baltimore.

Romer, P. (1990), “Endogenous Technological Change,” Journal of Political Economy, 98(5), Part 2, S71-S102.

Saggi, K. (2002), "Trade, Foreign Direct Investment, and International Technology Transfer: A Survey,” World Bank Research Observer, 17(2), 191-235.

Schiavo, S., Reyes, J., and Fagiolo, G. (2010), “International Trade and Financial Integration: A Weighted Network Analysis,” Quantitative Finance, 10(4), 389-399.

Shapiro, C. and Varian, H. (1998), Information Rules, Harvard Business School Press.

Solow, R. (1956), “A Contribution to the Theory of Economic Growth,” Quarterly Journal of Economics, 70(1), 65-94. 
Watts, D. (2003), Six Degrees: The Science of a Connected Age, W. W. Norton \& Company.

Wooldridge, J. (2002), Econometric Analysis of Cross Section and Panel Data, Cambridge, MA, MIT Press.

Xu, B. (2000), “Multinational Enterprises, Technology Diffusion, and Host Country Productivity Growth,” Journal of Development Economics, 62(2), 477-493.

Xu, B. and Wang, J. (1999), “Capital Goods Trade and R\&D Spillovers in the OECD,” Canadian Journal of Economics, 32(5), 1258-1274.

Xu, B, and Wang, J. (2000), “Trade, FDI, and International Technology Diffusion,” Journal of Economic Integration, 15(4), 585-601. 
Figure 1: Direct and Indirect Paths in the Trading Network

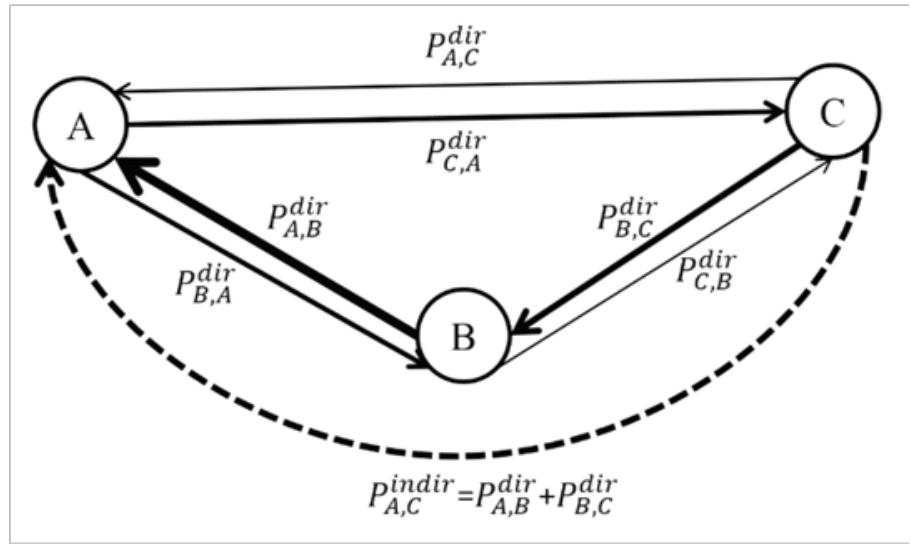


Figure 2 Cross-Country Average Technology Intensity Levels
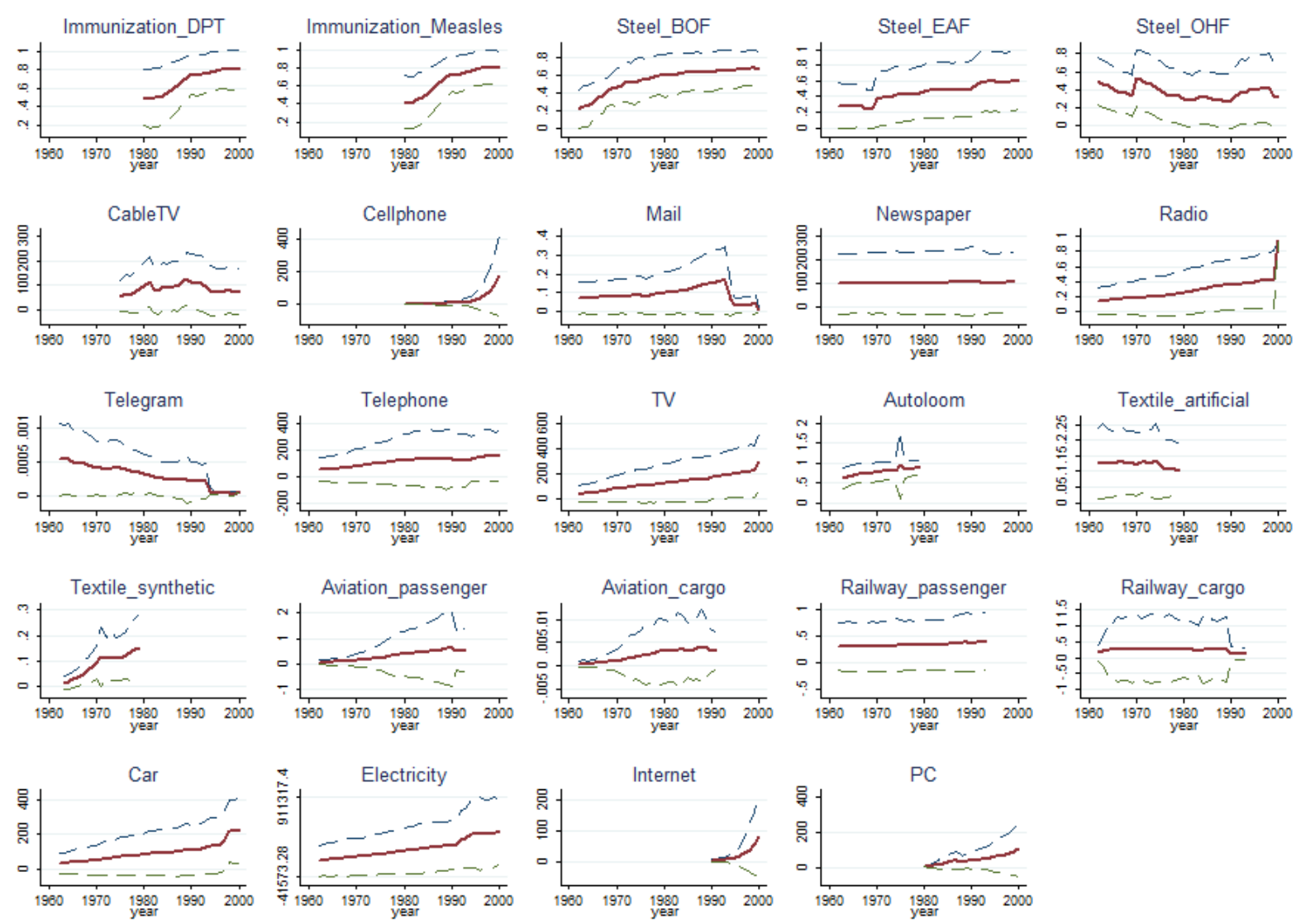

Note: The number of countries may vary across different technologies and different years. 
Figure 3: Estimates of the Distribution of Countries According to Log Intensity levels and Average Growth Rates of Cellphone and Telegram
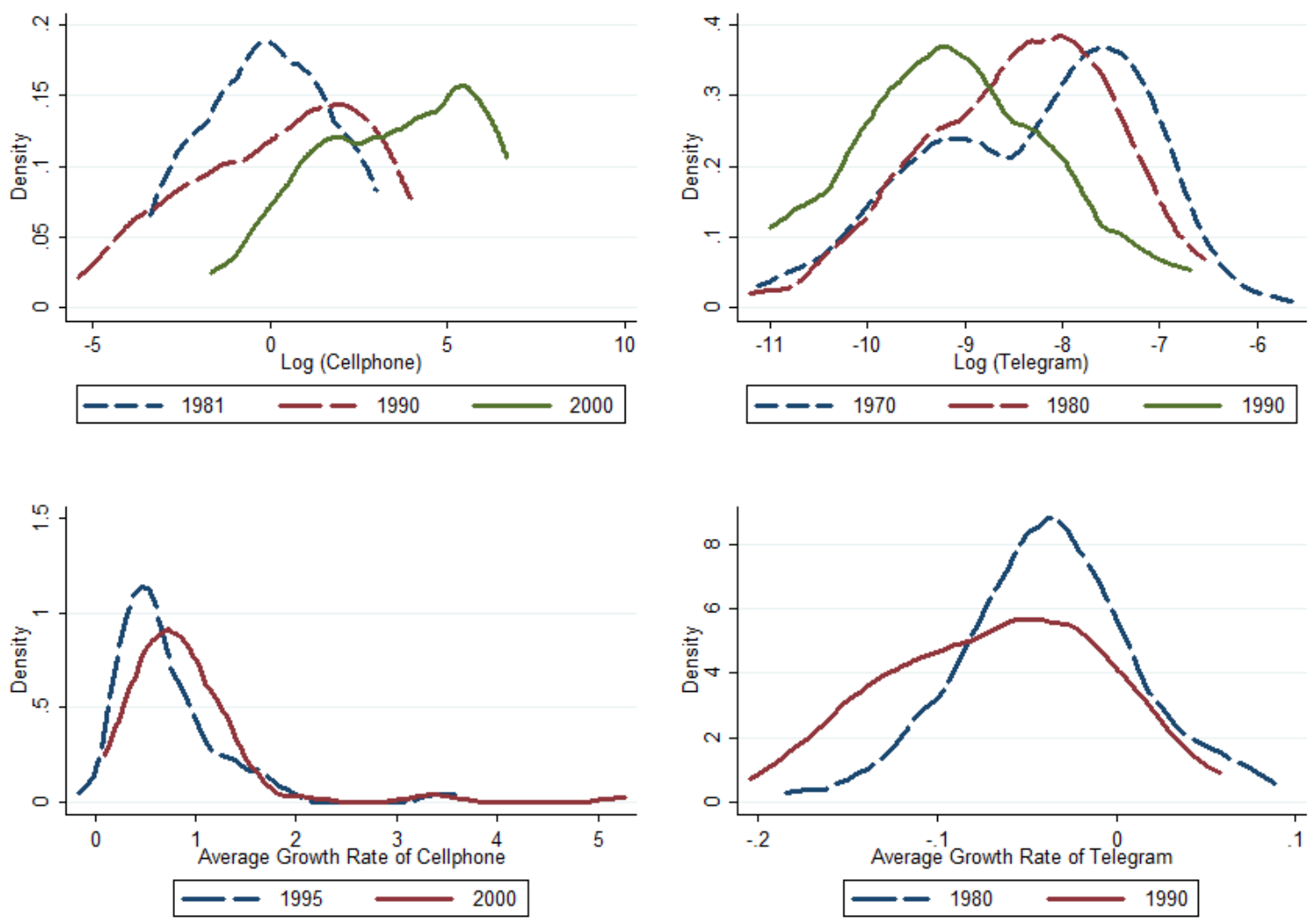

Notes: The above figure shows that, for both the log level and average growth rate measures, the relatively new technology "Cellphone" has distributions shifting rightward over time while the relatively old technology "Telegram” has distributions shifting leftward over time.

For "Cellphone" on the bottom left, the growth rate in 1995 refers to the geometric average of the growth rates between 1990 and 1995 and the growth rate in 2000 refers to the average between 1995 and 2000.

For "Telegram" on the bottom right, the growth rate in 1980 refers to the average between 1970 and 1980 and the growth rate in 1990 refers to the average between 1980 and 1990. 
Figure 4: Network Density
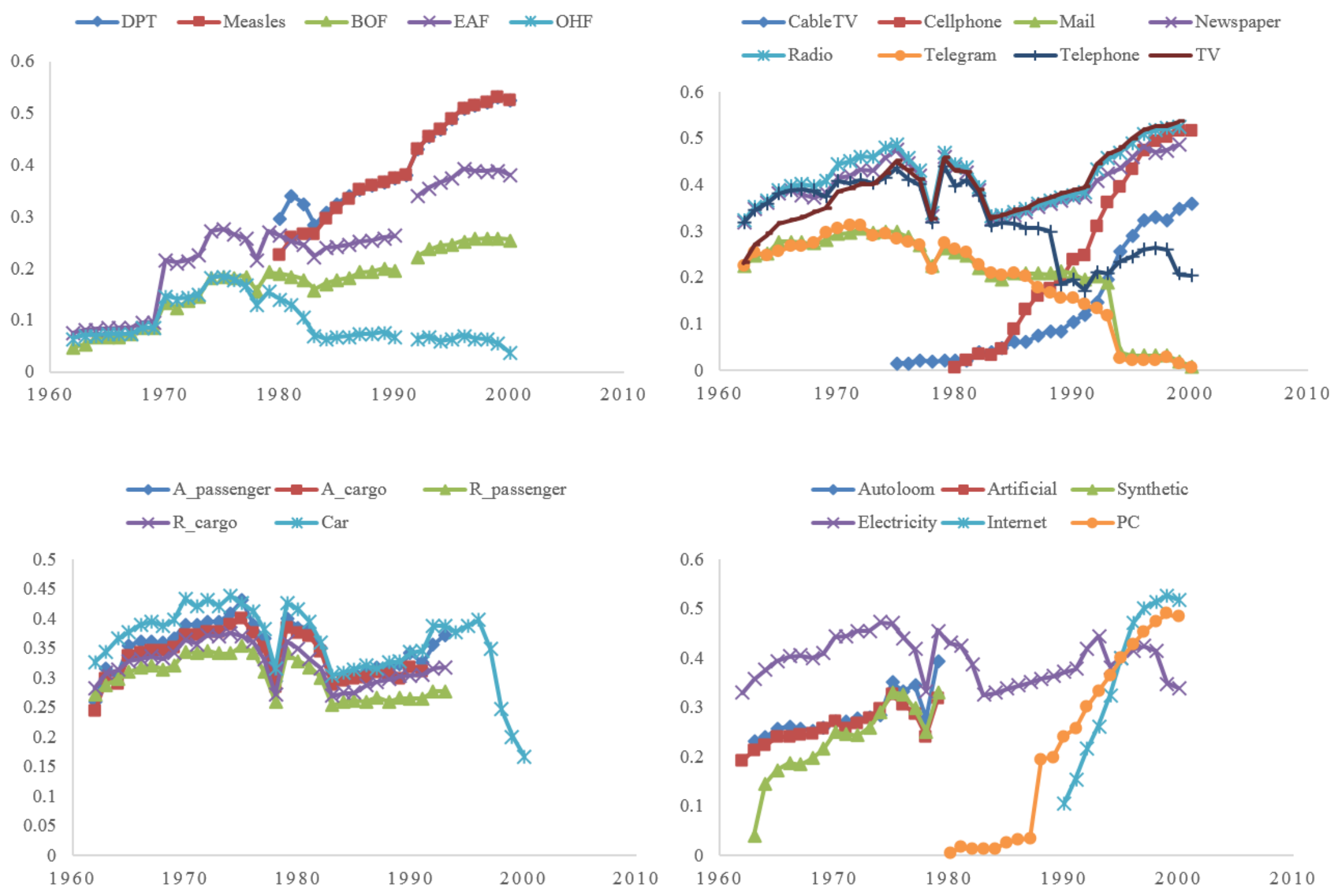
Table 1: Technology Intensity Variables and Descriptions

\begin{tabular}{|c|c|}
\hline INTENSITY VARIABLES & VARIBLE DESCRIPTION \\
\hline \multicolumn{2}{|l|}{ I. $H E A L T H$} \\
\hline 1. Immunization_DPT & $\begin{array}{l}\text { Percent of children aged } 12-23 \text { months who received a DPT (diphtheria, } \\
\text { pertussis, and tetanus) immunization (including all three doses) before the age } \\
\text { of one year }\end{array}$ \\
\hline 2. Immunization_measles & $\begin{array}{l}\text { Percent of children aged } 12-23 \text { months who received a measles immunization } \\
\text { (one dose only) before the age of one year }\end{array}$ \\
\hline \multicolumn{2}{|r|}{ 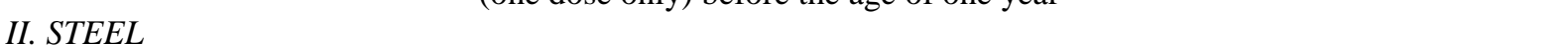 } \\
\hline 3. Steel_BOF & $\begin{array}{l}\text { Fraction of crude steel production (in metric tons) in blast oxygen furnaces (a } \\
\text { process that replaced Bessemer and OHF processes) }\end{array}$ \\
\hline 4. Steel_EAF & $\begin{array}{l}\text { Fraction of crude steel production (in metric tons) in electric arc furnaces (a } \\
\text { process that complemented and improved upon Bessemer and OHF processes) }\end{array}$ \\
\hline 5. Steel_OHF & $\begin{array}{l}\text { Fraction of crude steel production (in metric tons) in open hearth furnaces (a } \\
\text { process that complemented the Bessemer process) }\end{array}$ \\
\hline \multicolumn{2}{|l|}{ III. TELECOM } \\
\hline 6. CableTV & $\begin{array}{l}\text { Number of households that subscribe to a multi-channel television service } \\
\text { delivered by a fixed line connection per capita }\end{array}$ \\
\hline 7. Cellphone & Number of users of portable cell phones per capita \\
\hline 8. Mail & Number of items mailed/received per capita \\
\hline 9. Newspaper & Number of newspaper copies circulated daily per capita \\
\hline 10. Radio & Number of radios per capita \\
\hline 11. Telegram & Number of telegrams sent per capita \\
\hline 12. Telephone & $\begin{array}{l}\text { Number of mainline telephone lines connecting a customer's equipment to the } \\
\text { public switched telephone network per capita as of year end }\end{array}$ \\
\hline 13. TV & Number of television sets in use per capita \\
\hline \multicolumn{2}{|l|}{ IV. TEXTILES } \\
\hline 14. Autoloom & $\begin{array}{l}\text { Fraction of operable looms (of a certain size) in place at year end that are either } \\
\text { automatic or have automatic attachments (as opposed to ordinary looms) }\end{array}$ \\
\hline 15. Textile_artificial & Fraction of weight of fibers used in spindles that are artificial (cellulosic) \\
\hline 16. Textile_synthetic & Fraction of weight of fibers used in spindles that are synthetic (non-cellulosic) \\
\hline V. TRANSPORTATION & Civil aviation passenger-KM traveled on scheduled services by companies \\
\hline & registered in the country concerned per capita \\
\hline 18. Aviation_cargo & $\begin{array}{l}\text { Civil aviation ton-KM of cargo carried on scheduled services by companies } \\
\text { registered in the country concerned per unit of real GDP }\end{array}$ \\
\hline 19. Railway_passenger & Passenger journeys by railway in passenger-KM per capita \\
\hline 20. Railway_cargo & $\begin{array}{l}\text { Ton-KM of freight carried on railways (excluding livestock and passenger } \\
\text { baggage) per unit of real GDP }\end{array}$ \\
\hline 21. Car & $\begin{array}{l}\text { Number of passenger cars (excluding tractors and similar vehicles) in use per } \\
\text { capita }\end{array}$ \\
\hline \multicolumn{2}{|l|}{ VI. GENERAL } \\
\hline 22. Electricity & $\begin{array}{l}\text { Gross output of electric energy (inclusive of electricity consumed in power } \\
\text { stations) in KwHr per unit of real GDP }\end{array}$ \\
\hline 23. Internet & Number of people with access to the worldwide network per capita \\
\hline 24. PC & Number of self-contained computers designed for use by one person per capita \\
\hline
\end{tabular}


Table 2: Summary Statistics of Indirect Paths

\begin{tabular}{cccc}
\hline Technology & indir & indir_replace & dir_available \\
\cline { 2 - 3 } & total & dir_available & total \\
\hline Immunization_DPT & $98.14 \%$ & $96.45 \%$ & $47.75 \%$ \\
Immunization_measles & $98.11 \%$ & $96.32 \%$ & $48.22 \%$ \\
Steel_BOF & $94.63 \%$ & $93.51 \%$ & $18.00 \%$ \\
Steel_EAF & $95.34 \%$ & $94.38 \%$ & $20.81 \%$ \\
Steel_OHF & $91.85 \%$ & $87.62 \%$ & $26.14 \%$ \\
CableTV & $86.72 \%$ & $85.02 \%$ & $14.69 \%$ \\
Cellphone & $88.90 \%$ & $87.53 \%$ & $25.74 \%$ \\
Mail & $90.81 \%$ & $88.78 \%$ & $20.51 \%$ \\
Newspaper & $98.09 \%$ & $96.65 \%$ & $41.77 \%$ \\
Radio & $95.40 \%$ & $93.97 \%$ & $41.69 \%$ \\
Telegram & $87.97 \%$ & $85.06 \%$ & $22.87 \%$ \\
Telephone & $97.64 \%$ & $95.51 \%$ & $43.92 \%$ \\
TV & $97.99 \%$ & $96.50 \%$ & $40.72 \%$ \\
Autoloom & $97.09 \%$ & $95.94 \%$ & $25.40 \%$ \\
Textile_artificial & $96.95 \%$ & $95.72 \%$ & $24.39 \%$ \\
Textile_synthetic & $96.24 \%$ & $94.83 \%$ & $23.49 \%$ \\
Aviation_passenger & $97.68 \%$ & $96.31 \%$ & $36.45 \%$ \\
Aviation_cargo & $97.41 \%$ & $96.05 \%$ & $34.09 \%$ \\
Railway_passenger & $97.25 \%$ & $95.95 \%$ & $32.09 \%$ \\
Railway_cargo & $97.48 \%$ & $96.14 \%$ & $33.34 \%$ \\
Car & $97.76 \%$ & $96.29 \%$ & $38.28 \%$ \\
Electricity & $97.84 \%$ & $96.45 \%$ & $40.34 \%$ \\
Internet & $97.10 \%$ & $95.85 \%$ & $31.66 \%$ \\
PC & $86.43 \%$ & $81.76 \%$ & $29.22 \%$ \\
\hline
\end{tabular}

Notes: $\frac{\text { indir }}{\text { total }}$ measures the average percentage of indirect paths out of all the shortest paths.

$\frac{\text { indir_replace }}{\text { dir_available }}$, measures the average percentage of direct paths that are replaced by indirect shortest paths out of all the available direct paths.

$1-\frac{\text { dir_available }}{\text { total }}$, measures the average percentage of indirect shortest paths given no direct paths available out of all the shortest paths. 
Table 3: Summary Statistics of $D$ Used in the Benchmark Regressions

\begin{tabular}{cccccc}
\hline Technology & Obs. & Mean & Std. Dev. & Min & Max \\
\hline Immunization_DPT & 2243 & $2.31 \mathrm{E}-05$ & $3.54 \mathrm{E}-05$ & $3.92 \mathrm{E}-06$ & 0.000969 \\
Immunization_measles & 2194 & $3.03 \mathrm{E}-05$ & $5.51 \mathrm{E}-05$ & $3.71 \mathrm{E}-06$ & 0.001094 \\
Steel_BOF & 1240 & $5.43 \mathrm{E}-06$ & $3.07 \mathrm{E}-05$ & $2.21 \mathrm{E}-07$ & 0.000911 \\
Steel_EAF & 1869 & $1.36 \mathrm{E}-05$ & $1.89 \mathrm{E}-05$ & $1.38 \mathrm{E}-06$ & 0.000135 \\
Steel_OHF & 762 & 0.000017 & $3.15 \mathrm{E}-05$ & $2.19 \mathrm{E}-06$ & 0.00027 \\
CableTV & 662 & $6.36 \mathrm{E}-06$ & 0.000016 & $8.99 \mathrm{E}-10$ & $5.44 \mathrm{E}-05$ \\
Cellphone & 1191 & $1.05 \mathrm{E}-05$ & $9.36 \mathrm{E}-06$ & $1.51 \mathrm{E}-07$ & $3.08 \mathrm{E}-05$ \\
Mail & 1668 & 0.00027 & 0.000199 & $5.82 \mathrm{E}-06$ & 0.001189 \\
Newspaper & 3755 & $7.7 \mathrm{E}-06$ & $8.47 \mathrm{E}-06$ & $5.62 \mathrm{E}-07$ & 0.000049 \\
Radio & 3999 & 0.001071 & 0.004525 & $2.03 \mathrm{E}-05$ & 0.031423 \\
Telegram & 1612 & 0.042019 & 0.113242 & 0.004865 & 3.3143 \\
Telephone & 3202 & $2.15 \mathrm{E}-05$ & 0.000508 & $1.3 \mathrm{E}-06$ & 0.028709 \\
TV & 3777 & $1.83 \mathrm{E}-05$ & $2.17 \mathrm{E}-05$ & $1.96 \mathrm{E}-07$ & 0.000108 \\
Autoloom & 1018 & 0.000892 & 0.015194 & $1.82 \mathrm{E}-06$ & 0.48149 \\
Textile_artificial & 964 & 0.000082 & $5.02 \mathrm{E}-05$ & 0.000025 & 0.00068 \\
Textile_synthetic & 814 & 0.000153 & 0.000253 & $1.36 \mathrm{E}-05$ & 0.001523 \\
Aviation_passenger & 2682 & 0.011408 & 0.259034 & $4.58 \mathrm{E}-05$ & 13.341 \\
Aviation_cargo & 2420 & 1.193418 & 34.193 & 0.001917 & 1676.8 \\
Railway_passenger & 2203 & 0.000297 & 0.00026 & $4.64 \mathrm{E}-05$ & 0.001233 \\
Railway_cargo & 2431 & 0.000369 & 0.00034 & $9.25 \mathrm{E}-05$ & 0.0078 \\
Car & 3400 & $1.05 \mathrm{E}-05$ & 0.000289 & $4.15 \mathrm{E}-08$ & 0.016832 \\
Electricity & 3974 & $9.7 \mathrm{E}-10$ & $1.13 \mathrm{E}-08$ & $4.39 \mathrm{E}-12$ & $6.92 \mathrm{E}-07$ \\
Internet & 878 & $6.32 \mathrm{E}-05$ & $8.17 \mathrm{E}-05$ & $7.12 \mathrm{E}-08$ & 0.000283 \\
PC & 1043 & $3.99 \mathrm{E}-05$ & 0.000394 & $1.07 \mathrm{E}-07$ & 0.005741 \\
\hline
\end{tabular}

Notes: E-X means $10^{-x}$. 
Table 4: Fixed-Effects Regression Results $(\alpha=1)$

\begin{tabular}{|c|c|c|c|c|c|c|c|c|c|c|c|c|c|}
\hline & \multicolumn{2}{|c|}{ HEALTH } & \multicolumn{3}{|c|}{ STEEL } & \multicolumn{8}{|c|}{ TELECOMMUNICATION } \\
\hline & DPT & Measles & BOF & EAF & OHF & CableTV & Cellphone & Mail & Newspaper & Radio & Telegram & Telephone & TV \\
\hline \multirow[t]{2}{*}{ RGDP } & -.01103 & $.06259 * * *$ & -.01744 & $-.06683 * * *$ & $-.13302 * * *$ & $2.38232 * * *$ & .26009 & $.79838 * * *$ & $.24869 * * *$ & -.02074 & $.12915^{*}$ & $1.34310^{* * *}$ & $.40808^{* * *}$ \\
\hline & .01738 & .01804 & .02250 & .02070 & .03267 & .34510 & .30800 & .04121 & .02721 & .03035 & .06621 & .03167 & .06500 \\
\hline \multirow[t]{2}{*}{ Openness } & .00115 & -.01366 & $.08652 * *$ & $.10942^{* * *}$ & -.03834 & -.33172 & -.20692 & .07839 & -.02756 & $-.09386 * *$ & -.16048 & $.49447^{* * *}$ & -.07790 \\
\hline & .01532 & .01556 & .03683 & .02824 & .05837 & .31238 & .20994 & .06473 & .03665 & .04048 & .09801 & .04478 & .08170 \\
\hline \multirow[t]{2}{*}{ TW } & $.35468^{* * *}$ & $.27460 * * *$ & $.73754 * * *$ & $.54904 * * *$ & $1.28743^{* * *}$ & $.29314^{* * *}$ & $1.25201^{* * *}$ & $.01973 *$ & .05333 & $.62208^{* * *}$ & $.45253 * * *$ & $-.17745^{* * *}$ & $1.63784^{* * *}$ \\
\hline & .03594 & .03743 & .04176 & .05965 & .07705 & .07169 & .02396 & .01137 & .04341 & .04114 & .01711 & .01917 & .05133 \\
\hline D & $-.08531^{* * *}$ & $-.08838 * * *$ & -.00630 & $-.00799 * *$ & $-.01831 * *$ & $.10721^{* * *}$ & $-.19281^{* * *}$ & $.08299 * * *$ & $-.03772 * * *$ & $-.22344 * * *$ & $.18100^{* * *}$ & $-.14797 * * *$ & $-.24951^{* * *}$ \\
\hline \multirow{3}{*}{ Cons. } & .00429 & .00502 & .00389 & .00379 & .00836 & .01497 & .02484 & .01194 & .00809 & .00771 & .01837 & .00770 & .01333 \\
\hline & $-.52936 * * *$ & $-.56726 * * *$ & $.13288^{* * *}$ & $.27893^{* * *}$ & $.20689 *$ & $-1.33189 *$ & $-5.86350 * * *$ & $-3.72302 * * *$ & $2.55252 * * *$ & $-3.54093 * * *$ & $-4.18329 * * *$ & $.68630 * * *$ & $-9.23435 * * *$ \\
\hline & .03540 & .03641 & .03904 & .04782 & .11154 & .75382 & .56627 & .07362 & .28497 & .07877 & .12031 & .09565 & .23249 \\
\hline Adj-R ${ }^{2}$ & .7976 & .7731 & .7264 & .8295 & .8425 & .8944 & .9072 & .9671 & .9655 & .8894 & .8508 & .9649 & .8679 \\
\hline \# Obs. & 2243 & 2194 & 1240 & 1869 & 762 & 662 & 1191 & 1668 & 3755 & 3999 & 1612 & 3202 & 3777 \\
\hline
\end{tabular}


Table 4 (cont.): Fixed-Effects Regression Results $(\alpha=1)$

\begin{tabular}{|c|c|c|c|c|c|c|c|c|c|c|c|}
\hline & \multicolumn{3}{|c|}{ TEXTILE } & \multicolumn{5}{|c|}{ TRANSPORTATION } & \multicolumn{3}{|c|}{ GENERAL } \\
\hline & Autoloom & Artificial & Synthetic & A_passenger & A_cargo & R_passenger & R_cargo & Car & Electricity & Internet & $\mathrm{PC}$ \\
\hline \multirow[t]{2}{*}{ RGDP } & $.33121 * * *$ & -.01339 & $.06861 * * *$ & $1.46435^{* * *}$ & $.89207 * * *$ & $.41622 * * *$ & $-.59475^{* * *}$ & $1.04611^{* * *}$ & -.04379 & -.62575 & $1.19113^{* * *}$ \\
\hline & .07070 & .01504 & .02445 & .04021 & .06418 & .03960 & .04140 & .03695 & .02935 & .43846 & .15713 \\
\hline \multirow[t]{2}{*}{ Openness } & .09083 & $.04112 *$ & $.05921 *$ & $.37714 * * *$ & $.64215^{* * *}$ & $-.19521^{* * *}$ & $-.24638 * * *$ & $.10181^{* *}$ & $.14096 * * *$ & $-.64128 * *$ & $.39508^{* * *}$ \\
\hline & .11301 & .02474 & .03066 & .05509 & .08233 & .06392 & .06593 & .04964 & .03954 & .32575 & .12768 \\
\hline \multirow[t]{2}{*}{ TW } & -.17963 & $.24396 * *$ & $.19805^{*}$ & $.50907 * * *$ & $.51094 * * *$ & $.14641 * * *$ & $.16724 * * *$ & $.36525 * * *$ & $.21234 * * *$ & $1.49612^{* * *}$ & $1.27616^{* * *}$ \\
\hline & .15528 & .10979 & .11567 & .02082 & .02856 & .05418 & .02540 & .03021 & .02722 & .03027 & .03442 \\
\hline \multirow[t]{2}{*}{$\mathrm{D}$} & -.01136* & .00320 & $-.02406 * * *$ & $-.04107 * * *$ & $-.03915^{* * *}$ & $.03940 * * *$ & $.10201^{* * *}$ & $-.09352^{* * *}$ & $-.17525 * * *$ & $-.14204 * * *$ & $.06487 * * *$ \\
\hline & .00606 & .00498 & .00541 & .00774 & .01144 & .01086 & .01503 & .00811 & .00556 & .01796 & .01650 \\
\hline \multirow[t]{2}{*}{ Cons. } & $.32014 * * *$ & $.11964 * *$ & $-.27671^{* * *}$ & $-4.29382 * * *$ & $-5.25608 * * *$ & $-2.20457 * * *$ & $-1.12390 * * *$ & $-1.37353 * * *$ & $5.38341^{* * *}$ & $-4.79911^{* * *}$ & $-4.77985^{* * *}$ \\
\hline & .09147 & .04671 & .03722 & .08238 & .25347 & .08466 & .10728 & .13688 & .37725 & .68418 & .25664 \\
\hline Adj-R ${ }^{2}$ & .3764 & .7357 & .6501 & .9481 & .8587 & .9523 & .9542 & .9459 & .8836 & .9128 & .9530 \\
\hline \# Obs. & 1018 & 964 & 814 & 2682 & 2420 & 2203 & 2431 & 3400 & 3974 & 878 & 1043 \\
\hline
\end{tabular}

Notes: Significance levels: ***1\%, **5\%, *10\%.

Robust standard errors are in italics.

Definitions of dependent variables can be found in Table 1. 